\title{
Mental Health and Health Behaviour Changes for Mothers of Children with a Disability: Effectiveness of a Health and Wellbeing Workshop
}

\author{
Helen M. Bourke-Taylor ${ }^{1}\left[\right.$ [ $\cdot$ Kahli S. Joyce ${ }^{1} \cdot$ Sarah Grzegorczyn $^{2} \cdot$ Loredana Tirlea $^{3}$ \\ Accepted: 1 March 2021 / Published online: 16 March 2021 \\ (c) The Author(s), under exclusive licence to Springer Science+Business Media, LLC, part of Springer Nature 2021
}

\begin{abstract}
Healthy Mothers Healthy Families (HMHF) is a program that educates and empowers mothers of children with disabilities to improve health behaviours. Outcomes were investigated in this study. A pre, post-test design was implemented using online questionnaires including the Health promoting activities scale (HPAS) and the Depressional anxiety stress scales (DASS). Mothers $(\mathrm{N}=71)$ experienced improvements in HPAS scores, $\mathrm{p}<.001$. Mental health symptomatology reduced: depressive symptoms $(\mathrm{p}=.005)$, Anxiety symptoms $(\mathrm{p}=.005)$ and stress $(\mathrm{p}=.002)$. Wellbeing improved $(\mathrm{p}<.001)$. Mothers also reported that their child with a disability experienced an increase in quality of life $(\mathrm{p}=.042)$. Mothers' lifestyles goals improved: managing stress; dietary changes; leisure; self-perception and others. HMHF is an effective intervention with improved health status and outcomes for mothers.
\end{abstract}

Keywords Mothers $\cdot$ Childhood disability $\cdot$ Mental health $\cdot$ Wellbeing

Parenting a child with a disability is more demanding than parenting a typically developing child and requires significant time, attention and self-education (Bourke-Taylor et al., 2010; Luijkx et al., 2017; Tomiyama et al., 2018). Parents experience physical and mental health disparities indicating that family centred practice is essential to support the family unit (Chambers \& Chambers, 2015). Mothers are generally the primary carer, frequently experiencing enhanced life experience, as well as stress related to a gamut of additional care tasks including medical care, equipment management, behavioural management, and service navigation (Findler, 2016), and mothers assume additional roles such as case manager, therapist and teacher (Gagnon et al., 2020). Research indicates there is a significant disparity between

Helen M. Bourke-Taylor

helen.bourke-taylor@monash.edu

1 Occupational Therapy Department, School of Primary and Allied Health Care, Faculty of Medicine Nursing and Health Sciences, Monash University, Peninsula Campus, Building G, Level 4, McMahons road, Frankston, VIC 3199, Australia

2 Occupational Therapy Department, Peninsula Health, Hastings road, Frankston, VIC 3199, Australia

3 Faculty of Health, Arts, and Design, Swinburne University of Technology, PO Box 218, Hawthorn 3122, Australia the physical and mental health status of mothers of children with and without disabilities (Bourke-Taylor, Howie, et al., 2012; Bourke-Taylor, Law, et al., 2012; Gilson et al., 2018; Marquis et al., 2020).

Wellbeing is important for mothers of children with a disability because resilience and sustaining caregiving capacity are closely related concepts (Halstead et al., 2018). Maintaining parents' capacity to care long term is paramount to the wellbeing of children with disability (Collins et al., 2017). Coping strategies used by mothers to manage the care of their child have been extensively researched and a recent systematic review identified positive coping strategies as a predictor of child wellbeing and outcomes (Vernhet et al., 2019). However, this systematic review only briefly acknowledged the influence of external factors such as physical, mental and other behavioural and environmental influences on maternal coping and stress. Due to the complex nature of caring for a child with a disability, costs, availability of appropriate supports, family dynamics and family supports, it is likely that there are a plethora of factors influencing maternal coping.

Many childhood disability interventions that are delivered to parents revolve around the premise that parental health and wellbeing largely depends on the outcomes of the child with disability. Child focused interventions seek to improve parents' wellbeing by equipping parents with the skills and 
knowledge to manage their child's disability with greater ease (Furlong et al., 2013; Ruane \& Carr, 2019). A recent systematic review investigated the content, characteristics and the efficacy of interventions that aimed to improve the mental health of mothers of children with a disability. The systematic review found that about 90 percent of existing research prioritised child outcomes and parental outcomes were considered secondary (Bourke-Taylor et al., BourkeTaylor, Joyce, et al., 2021). Of the 31 papers targeting maternal mental health and wellbeing as the primary outcomes, the authors identified a range of programs with novel and tailored approaches that were broadly categorised as cognitive-behavioural approaches, psychoeducation and health education approaches, mindfulness approaches, and support group approaches. The systematic review and metanalysis concluded that cognitive behavioural approaches such as psychotherapy or cognitive behavioural therapy, and psychoeducation/health education approaches such as programs improving knowledge and behaviours around better mental, fitness/physical health and coping strategies, were effective at improving maternal stress and mental health (Bourke-Taylor et al., Bourke-Taylor, Joyce, et al., 2021). Fundamental to the health education interventions included in the review were the inclusion of activities that are beneficial to general health such as physical exercise, planning meals and making healthy dietary choices. Another recent systematic review concluded that health promotion programs aimed at parents are warranted in childhood disability services (Ogourtsova et al., 2019).

The aforementioned research supports the effectiveness of interventions that include health and wellbeing education with an emphasis on changing thoughts and cognition to influence positive behaviour change. The Healthy Mothers Healthy Families (HMHF) is a program that includes such content, is group based and professionally delivered within a workshop environment for mothers. The HMHF program was designed in response to research that identified factors that predict hardship and health disparity among mothers of children with higher care needs and time demands (Bourke-Taylor \& Jane, 2018). Healthy Mothers Healthy Families has been developed over eight years and was seeded in an exploratory mixed methods study that interviewed and examined the health and occupations of mothers of children with a disability (BourkeTaylor et al., 2010). The Health Promoting Activities Scale (HPAS) was developed as the primary outcome measure (Bourke-Taylor, Howie, et al., 2012; Bourke-Taylor, Law, et al., 2012; Muskett et al., 2017). The HMHF program utilises both a health education and promotion approach as well as a lifestyle redesign strategy to encourage mothers to increase the frequency that they participant in behaviours that support their health. These behaviours specifically included: planning a healthy routine; being physically active alone or with others; spending time out or in a spiritually meaningful way; spending time with socially supportive others; and being involved in meaningful quiet recreational pursuits alone or with others.

Past research included a time series, mixed methods evaluation of the HMHF program (Bourke-Taylor \& Jane, 2018; Bourke-Taylor et al., 2019). In the initial study, the HMHF intervention was delivered of $6,3 \mathrm{~h}$ sessions over 4 months and the program was facilitated by an occupational therapist and general practice physician, including other health experts (physiotherapists, psychologists). Findings included statistically significant improvements at the end of the intervention: maternal factors including healthy behaviours $(p=0.017)$, empowerment $(p=0.009)$, depressive symptoms $(p=0.017)$, anxiety $(p=0.016)$, stress $(\mathrm{p}=0.037)$; family factors including cohesion $(p=0.05)$; and the child's psychosocial quality of life $(p<0.001)$, with several, such as wellbeing $(p=0.001)$ were maintained at 12 weeks post intervention (BourkeTaylor et al., 2019).

The current project enabled the development of the program to include a single day workshop supported by an online learning package (six modules). Ongoing demand required upscale across two states in Australia and included newly trained peer facilitators, a six module online package, and a single day intervention. The aim of this quantitative study was to evaluate outcomes of the community delivered HMHF program. Research questions included:

(1) What significant changes do mothers of children with a disability report in regard to mental health, wellbeing and healthy behaviour six weeks post- participation in the HMHF program?

(2) What changes do mothers of children with a disability report regarding the frequency of service access and help seeking six weeks post- participation in the HMHF program?

(3) What significant changes do mothers report with regard to empowerment or child related quality of life six weeks post- participation in the HMHF program?

(4) What other changes do mothers report following six weeks post-participation in the HMHF intervention?

\section{Methods}

The current study employed a pre and post-test design with two data collection points, to evaluate the health, wellbeing and healthy behaviours of mothers of children with a disability prior to and following participation in the HMHF intervention. The workshops were funded by an Australian Government grant to deliver the workshop to mothers. 


\section{Procedures}

The pre-test, post-test design was configured around the administration of the free workshop that was delivered in the community. Due to the funding body, registration and attendance was encouraged and allowed regardless of participation in the research. Data were collected online using Qualtrics Research Platform, version February, 2018 (Qualtrics, 2018). This project was approved by the Monash University Human Research Ethics Committee (Project number 10960). The HMHF intervention was delivered within a workshop format with online modules.

\section{The Healthy Mothers Healthy Families Intervention}

The HMHF day workshop included a workbook, and access to a specially designed website with a 6-module online learning package. Twenty-three workshops were facilitated between 2018 and 2020 across rural and metropolitan regions of Victoria and Tasmania by an Occupational Therapist (the first author) and/or co-facilitated by trainee facilitators with a background in health and disability advocacy. The content and operation of the HMHF workshop is described in detail in Supplementary Table 1. The Template for Intervention Description and Replication (TiDIER) checklist (Hoffmann et al., 2014) was used to guide the workshop content and delivery and to enable a structured way to identify and maintain the core parts of the intervention as it was replicated 22 times. Further information on the HMHF credentialing process and efficacy is described elsewhere (Bourke-Taylor, Joyce, et al., 2021; Bourke-Taylor, Lee, et al., 2021). Workshops also included specialist input (face to face or video) from other health professionals, including a General Practitioner, Physiotherapist, Dietitian, and Counsellor, as well from other mothers with lived experience. Fidelity of the HMHF intervention was achieved by ensuring replicability and equivalence between workshops as described using the TiDIER table (see Supplementary Table 1), through provision of the same workshop content, resources and trained facilitators. Hence, participants received the same HMHF program regardless of where, when and who ran the workshop.

\section{Participants and Recruitment}

Inclusion criteria required that participants were mothers (birth, adoptive, foster) of a child with a diagnosed disability, able to complete the online questionnaires in English, and had registered to attend a HMHF workshop. Mothers were excluded if they were then unable to attend the workshop. A flyer advertising HMHF inviting mothers to register was distributed through not-for-profit childhood disability agencies. After mothers registered to attend a workshop, mothers received an email inviting them to participate in the research. Participation in the research was voluntary and registration for the workshop did not oblige participation in the research. Only mothers providing informed consent were included in the research.

\section{Instrumentation}

Questionnaires comprised demographic questions about the mother and child with a disability, and nine scales identified in previous research (Bourke-Taylor et al., 2019). Scales included the Depression and Anxiety Stress Scales (DASS-21), Health Promoting Activities Scale (HPAS), Psychological General WellBeing Index (PGWBI), Family Environment Scale - Cohesion subscale (FES-CS), Family Empowerment Scale (FES), Child's Challenging Behaviour Scale - version 2 (CCBS-2), Paediatric Quality of Life Inventory (PedsQL), Assistance to Participate Scale (APS), and My Family's Accessibility and Community Engagement (MyFACE). The last outcome measure was newly developed and measured the mothers rating of how accessible and engaged mothers perceived local community services and places from their family's perspective. This scale was included as initial development indicated that maternal mental health influenced family participation in community activities, important opportunities for children with disabilities. Table 1 presents explanation of the construct to be measured by the instrument, a succinct description, psychometric information and internal reliability of included scales at time 1 and time 2 .

\section{Data Analysis}

Data were analysed with using IBM SPSS version 27 for out of range and missing values. To evaluate if data was missing randomly a Little's missing completely at random test (Little's MCAR) was used to determine if data was missing at random or missing systematically (non-random) and this was not significant (Chi square $=631.43, d f=666, p=0.828$ ). As a result, all data was treated as missing at complete random. Listwise deletion was applied to conduct the main analyses.

Preliminary analyses were conducted to ensure the assumptions for the paired sample $t$-test were adequately met. Moderate violations of normality assumption were present for several scales including DASS depression, DASS anxiety and DASS stress. The score distribution was slightly skewed for these scales. Several outliers were also noted. To deal with skewness and outliers these scales were transformed using natural logarithms. Paired sample $t$-test were performed with and without transformed variables with the results indicating that variables skewness had minimal influence on the final results. Consequently, non-transformed variables were used for all analyses. 


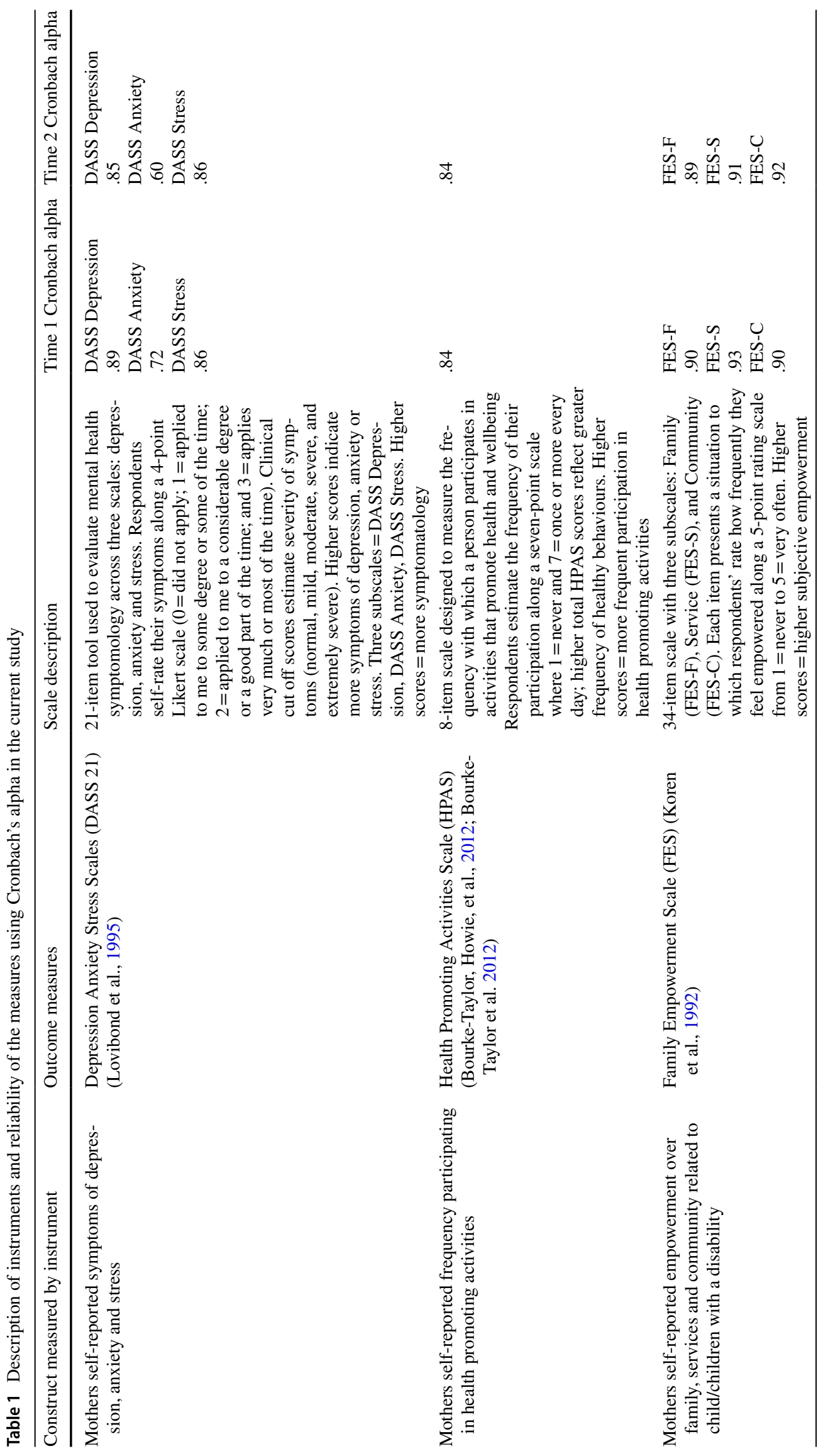




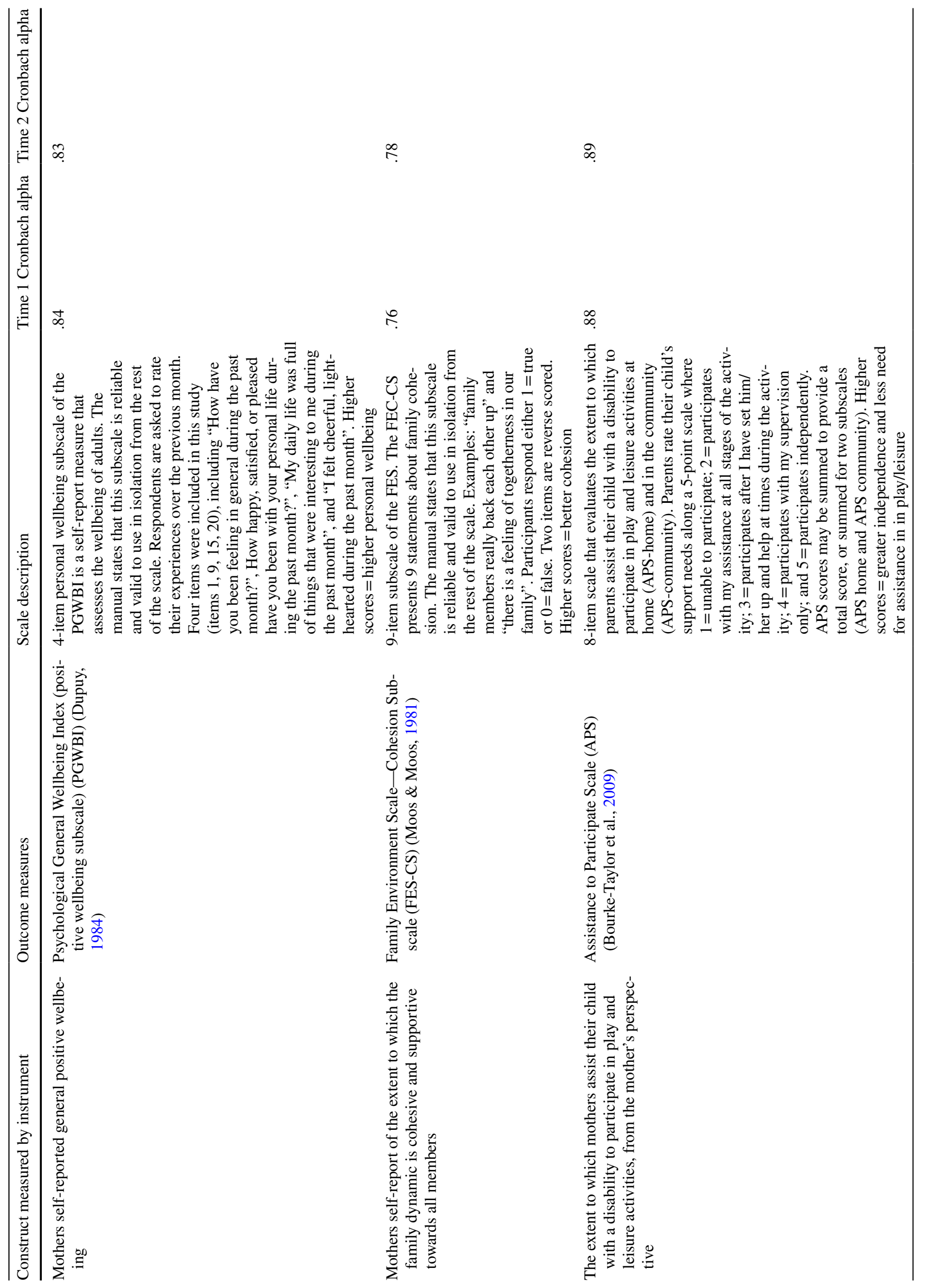




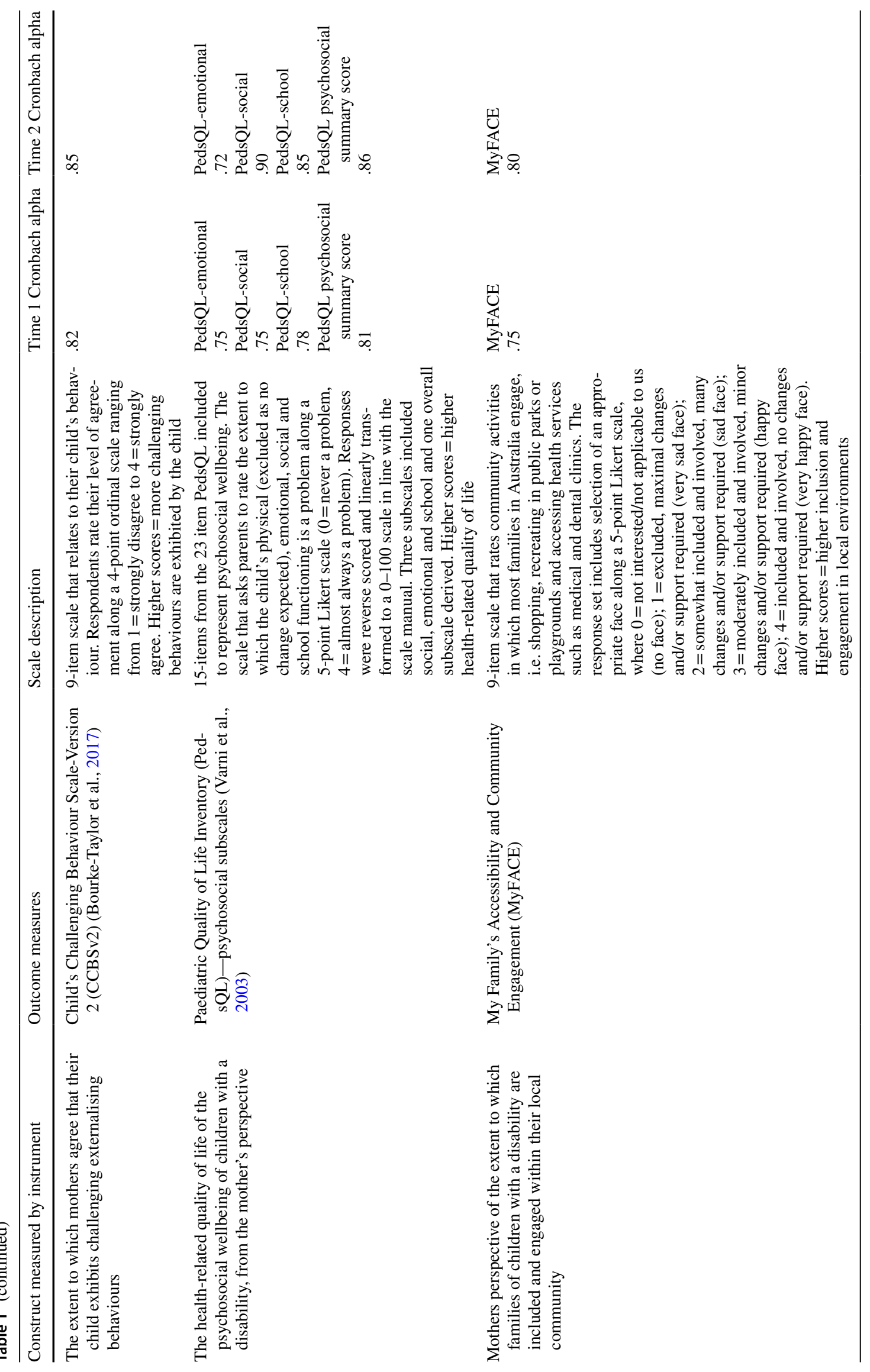


To address the first part of research question one, severity cut off scores were calculated for the DASS depression, anxiety and stress scores prior to the intervention and after the intervention. Percentages changes for participants classified as having normal, mild, moderate or more severe symptomatology were compared, within the group. To address research questions 1, 2 and 3, total scales scores and subscale scores examining mental health, wellbeing, participation in health promoting activities, frequency of service access and help seeking, changes in empowerment, attitudes to family community access or child related quality of life were compared between pre and post program assessments using paired sample $t$-test. Specifically analyses were conducted to compare pre and post intervention scores on the DASS (Depression, Anxiety and Stress subscales), Health Promoting Activities Scale (HPAS); The Psychological General Well Being Index (PGWB): (depressed mood; positive wellbeing; general health; vitality); Family Empowerment Scale: Family Subscale (FES-FS) (3 scores: family; services; community); Family Environment Scale: Cohesion subscale (FES-CS); My Family's Accessibility and Community Engagement (MyFACE); and frequency of service access and help seeking scales. A $p$-value of 0.05 was considered statistically significant for the inferential tests. Percentages were calculated to address research question 4. Change was assessed via nine questions.

\section{Results}

A total of 23 HMHF workshops were delivered to mothers who registered. Four hundred and seventy mothers registered to attend a HMHF workshop and 298 attended a workshop (see Fig. 1). Of the mothers who attended a workshop, 182 mothers participated in the research prior to the workshop (61\%) and 71 mothers (39\%) completed the research after the workshop. Thirty-six mothers who completed the prequestionnaire identified time restrictions and the COVID-19 pandemic as reasons that they did not complete the postquestionnaire. The other 75 mothers did not respond to a follow-up email to complete the post-questionnaire.

The current paper presents data on mothers who completed both the pre and post questionnaires $(\mathrm{N}=71$, see Table 2). Mothers had a mean age of 43 years $(\mathrm{SD}=7)$, resided in both rural (25\%) and metropolitan (75\%) regions across Victoria, and rural Tasmania. The majority of mothers were partnered or married (85\%), although six per cent were single. Mothers had completed a post-secondary school certificate or diploma (31\%), university undergraduate degree $(24 \%)$, or postgraduate degree $(27 \%)$. Just under half of mothers worked for pay (43\%).

The pre and post DASS scores were converted to clinical cut off scores and revealed a reduction in the number of participants with elevated symptomatology from pre to six weeks post intervention (see Table 3). Specifically, the number of mothers with elevated symptoms of depression,
Fig. 1 Flow chart of participants recruitment in the study

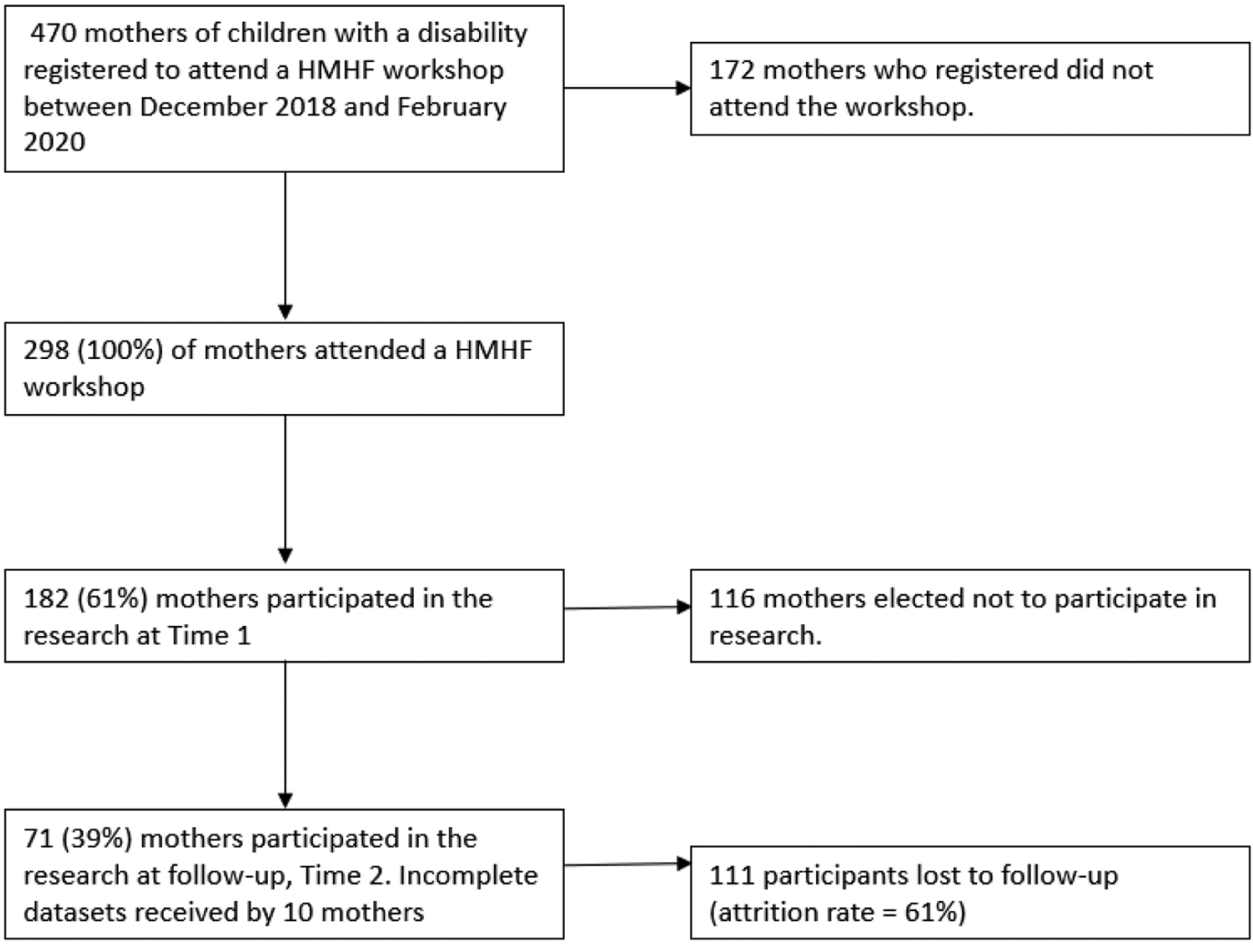


Table 2 Mother and child demographics $(\mathrm{N}=71)$

\begin{tabular}{|c|c|}
\hline Characteristics & Participant status, $\mathrm{n}(\% *)$ \\
\hline \multicolumn{2}{|l|}{ Mother characteristics } \\
\hline $\begin{array}{l}\text { Age } \\
\text { (years), mean (SD) range 27-68 years }\end{array}$ & $\begin{array}{l}43.50 \text { years } \\
\text { (SD } 7.31 \text { years) }\end{array}$ \\
\hline \multicolumn{2}{|l|}{ No of children in family $(n=65)$} \\
\hline One & $19(29 \%)$ \\
\hline Two & $32(49 \%)$ \\
\hline Three & $13(20 \%)$ \\
\hline Four or more & $1(1.5 \%)$ \\
\hline \multicolumn{2}{|l|}{ Income (AUD) $(n=63)$} \\
\hline Less than $\$ 50,000$ & $22(35 \%)$ \\
\hline Between $\$ 50,000$ and $\$ 80,000$ & $13(21 \%)$ \\
\hline Between $\$ 80,000$ and $\$ 150,000$ & $20(32 \%)$ \\
\hline Greater than $\$ 150,000$ & $8(13 \%)$ \\
\hline Child's characteristics & Status, $\mathrm{n}(\% *)$ \\
\hline Child's age, mean (SD) (range: 2 years to 36 years) & 10.6 years $(\mathrm{SD} 6.1)$ \\
\hline Children aged $0-2$ & $3(5 \%)$ \\
\hline Children aged $3-5$ years & $9(14 \%)$ \\
\hline Children aged $6-12$ years & $36(56.3 \%)$ \\
\hline Young people aged $13-21$ years & $13(20.3 \%)$ \\
\hline Young people $22-36$ & $4(6.3 \%)$ \\
\hline \multicolumn{2}{|l|}{ Child's gender } \\
\hline Boy & $47(70 \%)$ \\
\hline Girl & $20(30 \%)$ \\
\hline \multicolumn{2}{|l|}{ Child's education attendance $(n=64)$} \\
\hline Local primary school & $23(37 \%)$ \\
\hline Local secondary school & $3(4.8 \%)$ \\
\hline Special developmental school & $7(11 \%)$ \\
\hline Childcare/crèche & $10(14 \%)$ \\
\hline Other program & $4(5.6 \%)$ \\
\hline \multicolumn{2}{|l|}{ Child's disability $(\mathrm{N}=71)^{* *}$} \\
\hline Autism spectrum disorder & $44(62 \%)$ \\
\hline Cerebral palsy & $11(15.5 \%)$ \\
\hline Intellectual or learning disability & $19(27 \%)$ \\
\hline Depression/Anxiety & $17(24 \%)$ \\
\hline ADHD & $13(20 \%)$ \\
\hline Genetic disability/Chromosomal difference & $10(15.4 \%)$ \\
\hline Developmental delay & $5(7.7 \%)$ \\
\hline Down syndrome & $6(9.2 \%)$ \\
\hline Epilepsy & $4(6.2 \%)$ \\
\hline Hearing/vision loss & $4(6 \%)$ \\
\hline Other medical/disability & $34(48 \%)$ \\
\hline
\end{tabular}

*Percentages taken to full number, no decimal places and therefore may add up to 101 or 99

**Percentages do not add up to $100 \%$ as 'select all that apply' anxiety and stress reduced by $23 \%, 30 \%$ and $23 \%$ respectively. After 6 weeks, the number of mothers with elevated symptoms reduced: depression (from 57 to $34 \%$ ), anxiety (from 51 to 21\%) and stress (from 60 to $37 \%$ ).

Further differences from pre to six weeks post workshop were investigated using paired samples $t$-tests (see
Table 4). As expected, the intervention was found on average to significantly decrease DASS levels on all the three subscales (depression, anxiety and stress subscales). Further, as expected, significant gains were recorded post intervention on average for the positive wellbeing scale of the PGWBI, the HPAS, the FES (Family and Service 
Table 3 Summary of mothers' mental health status pre and post intervention

\begin{tabular}{lll}
\hline Mental health condition & $\begin{array}{l}\text { Participant status, } \\
\mathrm{n}\left(\%^{*}\right)\end{array}$ & $\begin{array}{l}\text { Participant } \\
\text { status, } \\
(\% *)\end{array}$ \\
& Pre & Post \\
\hline $\begin{array}{ll}\text { Depression anxiety stress scale } \\
\text { scores }\end{array}$ & & \\
Depression subscale scores Mean & $12.55(9.3)$ & $7.74(6.8)$ \\
(SD) & & \\
Normal & $70(43 \%)$ & $45(66 \%)$ \\
Mild & $22(13 \%)$ & $8(12 \%)$ \\
Moderate & $48(29 \%)$ & $12(18 \%)$ \\
Severe & $12(7 \%)$ & $1(2 \%)$ \\
Extremely severe & $12(7 \%)$ & $2(3 \%)$ \\
Anxiety subscale scores Mean (SD) & $8.15(\mathrm{SD}=6.3)$ & $5.58(7.9)$ \\
Normal & $79(49 \%)$ & $52(79 \%)$ \\
Mild & $20(12 \%)$ & $4(6 \%)$ \\
Moderate & $41(25 \%)$ & $7(11 \%)$ \\
Severe & $12(8 \%)$ & $1(2 \%)$ \\
Extremely severe & $11(7 \%)$ & $2(3 \%)$ \\
Stress subscale scores Mean (SD) & $18.88(\mathrm{SD}=9.1)$ & $15.28(8.3)$ \\
Normal & $66(40 \%)$ & $42(63 \%)$ \\
Mild & $26(16 \%)$ & $7(11 \%)$ \\
Moderate & $33(20 \%)$ & $9(14 \%)$ \\
Severe & $31(19 \%)$ & $6(9 \%)$ \\
Extremely severe & $10(7 \%)$ & $3(4 \%)$ \\
\hline
\end{tabular}

*Percentages taken to full number, no decimal places and therefore may add up to 101 or 99

**Percentages do not add up to $100 \%$ as select all that apply

subscales) and the PedsQ1 (Psychosocial Health Summary subscale). Unexpectedly, on average, no significant changes were recorded on FES-CS; CCBS-2 and MyFACE (see Table 4).

Unexpectedly, there was no significant change $(t(77)=1.52, p=0.13)$ on average in the frequency of service access and help seeking following participation in the HMHF program (before program, $M=2.86, S D=1.13$ ) and (after the program, $M=3.04, S D=1.06$ ). Actual changes 6 weeks after attendance at the workshop were calculated as percentage agreement with items. From highest to lowest percentage change $(n=70)$, results were: "Changes to my mental health and wellbeing" $(\mathrm{n}=28,40 \%)$; "Changes to my physical activity" ( $\mathrm{n}=28,40 \%)$; "Changes to how I view myself" ( $n=27,39 \%)$; "Changes to my leisure routine and participation in healthy activity" $(\mathrm{n}=26,37 \%)$; "Changes to my diet" $(n=26,37 \%)$; "Changes to the way I manage stress in my daily life" $(\mathrm{n}=22,31 \%)$; "Changes to the people that I spend time with" $(\mathrm{n}=17,24 \%)$; "Changes to my family's leisure routine" $(\mathrm{n}=15,21 \%)$; and "Changes to the way we manage stress in my family" ( $\mathrm{n}=14,20 \%)$.

\section{Discussion}

The HMHF single day workshop intervention coupled with a workbook and access to a six module online learning package was effective at significantly reducing mental health symptomatology and improving maternal personal wellbeing, participation in healthy activity, maternal empowerment and the mothers report of her child's psychosocial quality of life. No significant changes were detected in mothers' ratings of their child's challenging behaviour, family cohesion, frequency of maternal health service use or mothers' perceptions of family community engagement. Although mothers did not report increasing health practitioner services use, one quarter of mothers reported changes in depression, anxiety and stress symptomatology that placed mothers within the 'normal' group for these symptoms, rather than the elevated group. The vast majority of mothers who participated in this research were qualified at post school $(31 \%)$ or university level (53\%), mainly married (85\%), mothering boys (70\%) and a child with ASD (62\%). These findings indicate that the HMHF intervention effectively promoted the development of maternal self-management skills over six weeks for a diverse group of mothers.

Around $40 \%$ of mothers in this study reported significant changes in mental health, physical activity, healthy eating, managing stress and how mothers viewed themselves. Mothers reported that their child's psychosocial wellbeing significantly improved and one in five mothers rated their family leisure time as improved. Mothers felt more empowered in the family life and management of their child's disability services, although mothers' perception of community inclusion did not change in six weeks. Mothers did not report a significant reduction in their perception of challenging behaviours in the current study. Challenging behaviour is a substantial issue for mothers with higher stress and effective child directed behavioural interventions that are parent implemented (Tellegen \& Sanders, 2013) may be required in addition to HMHF for mothers in this group.

To date, HMHF is the only mother-focused intervention that delivered healthy lifestyle redesign, psycho-education and health education in a single day workshop that is therapeutic and a peer-mentor led group, with follow-up resources (workbook and website). Past research includes only one other peer mediated, individually delivered intervention with similar health and psychoeducation content that aimed to provide mothers with knowledge around health, mental health, stress, anxiety and coping strategies to improve their health and wellbeing. Magana and colleagues (Magana et al., 2015) conducted a randomised controlled trial to evaluate the efficacy of a peer-mediated, 


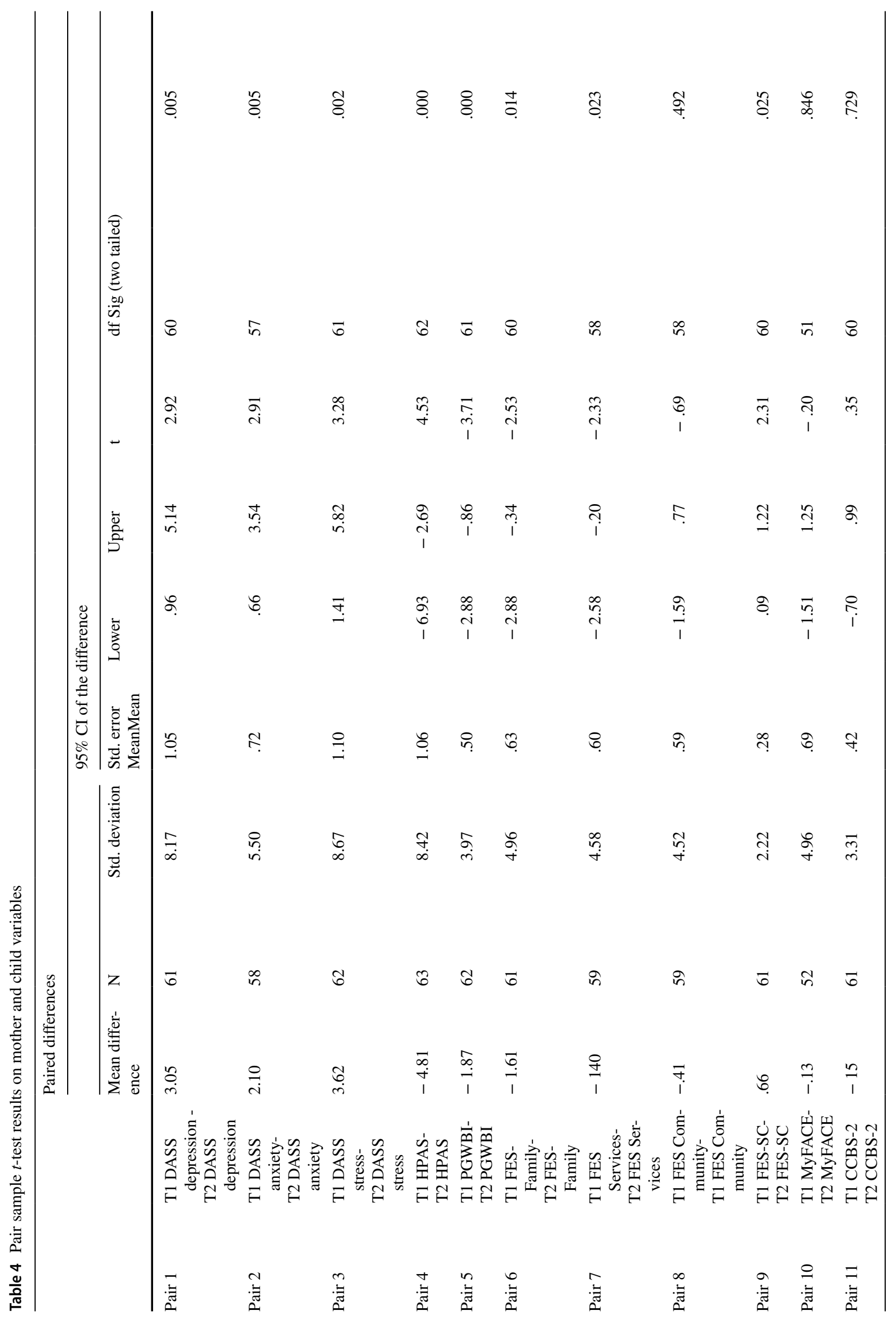


culturally sensitive, manualised health education intervention for mothers of children with disabilities. The intervention group of mothers $(n=42)$ received peer-to-peer intervention in their own homes. The intervention consisted of eight weekly sessions on various topics relevant maternal health (Magana et al., 2015). The intervention group showed significant improvements in health-related self-efficacy, and participation in self-care, nutrition and overall health behaviours compared to the control group. Both groups reported reduced depressive symptoms and carer burden. These results support the efficacy of peerto-peer programs on maternal health outcomes amongst mothers of children with a disability. In comparison, HMHF is a less onerous, single day workshop with manual and website and is group based, and therefore likely more cost effective. Future research might investigate outcomes for group versus individualised interventions and longer term outcomes overall.

Programs that aim to improve maternal wellbeing have rarely been peer lead. Examples of past research that has effectively improved mental health symptomology through individual or group approaches have been based in a cognitive-behavioural approach (Anclair \& Hiltunen, 2014; Feinberg et al., 2014; Osborn et al., 2018). Group interventions have included a support component and found a significant reduction in mothers' self-reported symptoms of depression, anxiety and stress (Shu \& Lung, 2005; Wei et al., 2012). It is important to note that none of the programs used co-design or co-delivery or use of technology for online delivery of supporting materials. Future research might continue to explore the efficacy of peer co-designed and co-lead interventions and different modes of intervention delivery (face to face, individual, group, online etc.).

Findings in the current study are important for mothers and their children. Childhood health literature recognises the significance of a healthy, responsive and well-resourced caregiver to a child's physical, cognitive and social-emotional development (Smith-Nielsen et al., 2016). This is especially important for children who have a disability and/or higher care needs, and whom are considered developmentally vulnerable (Collins et al., 2017). Mothers are known to express needs for accessible and practicable formal and informal supports (Gilson et al., 2018). Within family-centred practice, Mothers' perspectives are essential to optimal delivery of child services (King et al., 2017). Targeted support to empower mothers to look after their own health and wellbeing can have a flow-on effect to their own, and their child's functioning and health-related quality of life (Smith-Nielsen et al., 2016).

Limitations of the current research include loss to follow-up, which may introduce attrition bias. The funding source for the project was primarily to provide the HMHF intervention as an intervention and service to mothers. 
Mothers were free to attend and not participate or withdraw from the research, thus limiting the sample size. Future research may recruit a larger sample size through a different design that opted participants in or out of the intervention and studied outcomes, rather than provision of the workshop with optional research participation. Further, future research may have longer term follow-up to investigate if behaviour changes are sustained over time. Other limitations include lack of a control group or comparative group. Future research might include randomisation and a control group to determine comparative efficacy of HMHF.

Another potential limitation includes the practical aspect of being well resourced enough to locate, register and attend a workshop that requires child care for mothers. For example, $36 \%$ of mothers who registered were unable to attend the workshop on the day due to lack of a suitable carer, child being unwell, mother being unwell, another family member's needs or another reason. In future, a possible solution to increase availability of the HMHF workshops and related research activity might be to explore online delivery to neutralise access barriers experienced by mothers. This strategy may also increase research uptake and be the subject of future research.

The current study and the research described in this paper all contribute to furthering ways to better support families raising children with a disability. All family members need more supports and specifically designed appropriate programs that maintain health and wellbeing of individuals will support families as a whole (). As discovered in the recent systematic review of interventions aimed at reducing maternal stress and improving maternal mental health, the impact on mothers is internationally recognised and locally addressed in many countries (Bourke-Taylor, Joyce, et al., 2021; Bourke-Taylor, Lee, et al., 2021). However, across cultures and regions, there remains a common service gap for mothers who provide the majority of care in many families. Ways to build in the availability of a responsive program such as HMHF, or another culturally appropriate program, within the disability, health and education system within a region, must remain a focus in most countries (Collins et al., 2017). The findings from the current study are encouraging for three main reasons: (1) the results suggest that a short term intervention that is peer delivered supports mothers to make healthy behaviour change and improve their own wellbeing; (2) Group based interventions are well received by mothers as gauged by registrations; and (3) Blended interventions involving face to face and online modes are well received and effective for mothers. These and other learnings from the current study, as well as a recent systematic review (Bourke-Taylor, Joyce, et al., 2021; Bourke-Taylor, Lee, et al., 2021), may inform future research and program development internationally.
In conclusion, HMHF is an innovative program that addresses a crucial service gap in the disability sector: protecting the health status and health outcomes of mothers who are primary carers. In this study, participants demonstrate the ability to improve their own mental health, wellbeing and healthy behaviours after six weeks. The downstream effects for children with a disability included improved psychosocial wellbeing and a healthy mother with improved capacity to provide and sustain their care.

Supplementary Information The online version contains supplementary material available at https://doi.org/10.1007/s10803-021-04956-3.

Acknowledgments The authors acknowledge that this project was funded by the Australian Government, National Disability Insurance Agency, Information and Linkages Grant, 2018-2020.

Author Contributions HBT designed the study, delivered the intervention, collected data and wrote the manuscript; $\mathrm{KJ}$ assisted with the research project and parts of the manuscript; SG assisted in the research design and manuscript; LT completed data analysis and contributed to the manuscript.

\section{Compliance with Ethical Standards}

Conflict of interest All authors declare that they have no conflict of interest.

Ethical Approval All procedures performed in this study were in accordance with the ethical standards of 1964 Helsinki declaration and its later amendments or comparable ethical standards.

\section{References}

Anclair, M., \& Hiltunen, A. J. (2014). Cognitive behavioral therapy for stress-related problems: Two single-case studies of parents of children with disabilities. Clinical Case Studies, 13(6), 472-486. https://doi.org/10.1177/1534650114522090

Bourke-Taylor, H., Howie, L., \& Law, M. (2010). Impact of caring for a school-aged child with a disability: Understanding mothers' perspectives. Australian Occupational Therapy Journal, 57(2), 127-136. https://doi.org/10.1111/j.1440-1630.2009.00817.x

Bourke-Taylor, H., Howie, L., Law, M., \& Pallant, J. F. (2012). Selfreported mental health of mothers with a school-aged child with a disability in Victoria: A mixed method study. Journal of Paediatrics and Child Health, 48(2), 153-159. https://doi.org/10.1111/j. 1440-1754.2011.02060.x

Bourke-Taylor, H., \& Jane, F. (2018). Mothers' experiences of a women's health and empowerment program for mothers of a child with a disability. Journal of Autism and Developmental Disorders, 48(6), 2174-2186. https://doi.org/10.1007/s10803-018-3486-0

Bourke-Taylor, H., Law, M., Howie, L., \& Pallant, J. F. (2009). Development of the assistance to participate scale (APS) for children's play and leisure activities. Child Care Health and Development, 35(5), 738-745. https://doi.org/10.1111/j.1365-2214.2009. 00995.x

Bourke-Taylor, H. M., Jane, F., \& Peat, J. (2019). Healthy mothers healthy families workshop intervention: A preliminary investigation of healthy lifestyle changes for mothers of a child with 
a disability. Journal of Autism and Developmental Disorders, 49(3), 935-949. https://doi.org/10.1007/s10803-018-3789-1

Bourke-Taylor, H. M., Joyce, K., \& Grzegorczyn, S. (2021). Peer mentor training: Pathway to competency for facilitators of healthy mothers healthy families. Child Care Health Development. https://doi.org/10.1111/cch.12865

Bourke-Taylor, H. M., Law, M., Howie, L., \& Pallant, J. F. (2012). Initial development of the health promoting activities scale to measure the leisure participation of mothers of children with disabilities. American Journal of Occupational Therapy, 66(1), e1-e10. https://doi.org/10.5014/ajot.2012.000521

Bourke-Taylor, H. M., Lee, D. A., Tirlea, L., Joyce, K., Morgan, P., \& Haines, T. (2021). Interventions to improve the mental health of mothers of children with a disability: Systematic review, meta-analysis and description of interventions. Journal of Autism and Developmental Disorders. https://doi.org/10. 1007/s10803-020-04826-4

Bourke-Taylor, H. M., Pallant, J. F., \& Cordier, R. (2017). Child's challenging behaviour scale, version 2 (CCBS-2): Psychometric evaluation with young children. American Journal of Occupational Therapy, 71(4), 1-10. https://doi.org/10.5014/ajot.2017. 021733

Chambers, H. G., \& Chambers, J. A. (2015). Effects of caregiving on the families of children and adults with disabilities. Physical Medicine and Rehabilitation Clinics of North America, 26(1), 1-19. https://doi.org/10.1016/j.pmr.2014.09.004

Collins, P. Y., Pringle, B., Alexander, C., Darmstadt, G. L., Heymann, J., Huebner, G., Kutlesic, V., Polk, C., Sherr, L., Shih, A., Sretenov, S., \& Zindel, M. (2017). Global services and support for children with developmental delays and disabilities: Bridging research and policy gaps. PLoS Medicine, 14(9), e1002393. https://doi.org/10.1371/journal

Dupuy, H. J. (1984). The psychological general well-being (PGWB) index. In: N. K., Wenger, M. E., Mattson, C. D., Furberg, \& J. Elinson (Eds.), Assessment of quality of life in clinical trials of cardiovascular therapies (Chap. 9, pp. 170-183). Le Jacq Publishing.

Feinberg, E., Augustyn, M., Fitzgerald, E., Sandler, J., Ferreira-Cesar Suarez, Z., Chen, N., Cabral, H., Beardslee, W., \& Silverstein, M. (2014). Improving maternal mental health after a child's diagnosis of autism spectrum disorder: results from a randomized clinical trial. JAMA Pediatrics, 168(1), 40-46. https://doi.org/10.1001/ jamapediatrics.2013.3445

Findler, L., \& Ayelet KleinGabis, K. L. (2016). Subjective happiness among mothers of children with disabilities: The role of stress, attachment, guilt and social support. Research in Developmental Disabilities, 55, 44-54. https://doi.org/10.1016/j.ridd.2016.03.006

Furlong, M., McGilloway, S., Bywater, T., Hutchings, J., Smith, S. M., \& Donnelly, M. (2013). Cochrane review: Behavioural and cognitive-behavioural group-based parenting programmes for earlyonset conduct problems in children aged 3 to 12 years (Review). Evidence-Based Child Health Journal, 8(2), 318-692. https://doi. org/10.1002/ebch.1905

Gagnon, R. J., Garst, B. A., Kouros, C. D., Schiffrin, H. H., \& Cui, M. (2020). When overparenting is normal parenting: Examining child disability and overparenting in early adolescence. Journal of Child and Family Studies, 29(2), 413-425. https://doi.org/10. 1007/s10826-019-01623-1

Gilson, K. M., Davis, E., Johnson, S., Gains, J., Reddihough, D., \& Williams, K. (2018). Mental health care needs and preferences for mothers of children with a disability. Child Care Health and Development, 44(3), 384-391. https://doi.org/10.1111/cch.12556

Halstead, E. J., Ekas, N. V., Hastings, R., \& Griffith, G. M. (2018). Associations between resilience and the well-being of mothers of children with autism spectrum disorder and other developmental disabilities. Journal of Autism and Developmental Disorders, 48(4), 1108-1121. https://doi.org/10.1007/s10803-017-3447-z

Hoffmann, T., Glasziou, P., Boutron, I., Milne, R., Perera, R., Moher, D., Altman, D., Barbour, V., Macdonald, H., Johnston, M., Lamb, S., Dixon-Woods, M., McCulloch, P., Wyatt, J., Chan, A., \& Michie, S. (2014). Better reporting of interventions: Template for intervention description and replication (TIDieR) checklist and guide. British Medical Journal, 348, g1687. https://doi.org/ 10.1136/bmj.g1687

King, G., Williams, L., \& Hahn Goldberg, S. (2017). Family-oriented services in pediatric rehabilitation: A scoping review and framework to promote parent and family wellness. Child: Care, Health and Development, 43(3), 334-347. https://doi.org/10.1111/cch. 12435

Koren, P. E., DeChillo, N., \& Friesen, B. J. (1992). Measuring empowerment in families whose children have emotional disabilities: A brief questionnaire. Rehabilitation Psychology. https://doi.org/10. 1037/h0079106

Lovibond, S. H., Lovibond, P. F., \& Psychology Foundation of, A. (1995). Manual for the depression anxiety stress scales. Psychology Foundation of Australia.

Luijkx, J., van der Putten, A. A. J., \& Vlaskamp, C. (2017). Time use of parents raising children with severe or profound intellectual and multiple disabilities. Child Care, Health and Development, 43(4), 518-526. https://doi.org/10.1111/cch.12446

Magana, S., Li, H., Miranda, E., \& Paradiso de Sayu, R. (2015). Improving health behaviours of Latina mothers of youths and adults with intellectual and developmental disabilities. Journal of Intellectual Disability Research, 59(5), 397-410. https://doi. org/10.1111/jir.12139

Marquis, S. M., McGrail, K., \& Hayes, M. (2020). Mental health of parents of children with a developmental disability in British Columbia, Canada. Journal of Epidemiology and Community Health, 74(2), 173. https://doi.org/10.1136/jech-2018-211698

Moos, R. H., \& Moos, B. S. (1981). Family environment scale manual. Consulting Psychologists Press.

Muskett, R., Bourke-Taylor, H. M., \& Hewitt, A. (2017). Intrarater reliability and other psychometrics of the health promoting activities scale (HPAS). American Journal of Occupational Therapy, 71(4), 1-8. https://doi.org/10.5014/ajot.2017.021162

Ogourtsova, T., O’Donnell, M., De Souva Silva, W., \& Majnemer, A. (2019). Health coaching for parents of children with developmental disabilities: A systematic review. Developmental Medicine and Child Neurology, 61(11), 1259-1265. https://doi.org/10.1111/ dmcn.14206

Osborn, R., Girgis, M., Morse, S., Sladakovic, J., Kneebone, I., Shires, A., Durvasula, S., \& Roberts, L. (2018). Mindfulnessintegrated cbt (micbt) for reducing distress in parents of children with intellectual disability (id): A case series. Journal of Developmental and Physical Disabilities. https://doi.org/10.1007/ s10882-018-9602-4

Ruane, A., \& Carr, A. (2019). Systematic review and meta-analysis of stepping stones triple $\mathrm{P}$ for parents of children with disabilities. Family Process, 58(1), 232-246. https://doi.org/10.1111/famp. 12352

Shu, B. C., \& Lung, F. W. (2005). The effect of support group on the mental health and quality of life for mothers with autistic children [Clinical Trial Research Support, Non-U.S. Gov't]. Journal of Intellectual Disability Research, 49(Pt 1), 47-53. https://doi.org/ 10.1111/j.1365-2788.2005.00661.x

Smith-Nielsen, J., Tharner, A., Krogh, M. T., \& Vaever, M. S. (2016). Effects of maternal postpartum depression in a well-resourced sample: Early concurrent and long-term effects on infant cognitive, language, and motor development. Scandinavian Journal of Psychology, 57(6), 571-583. https://doi.org/10.1111/sjop.12321 
Tellegen, C. L., \& Sanders, M. R. (2013). Stepping stones triple p-positive parenting program for children with disability: A systematic review and meta-analysis. Research in Developmental Disabilities, 34(5), 1556-1571. https://doi.org/10.1016/j.ridd.2013.01.022

Tomiyama, S., Kikuchi, M., Yoshimura, Y., Hasegawa, C., Ikeda, T., Saito, D. N., Kumazaki, H., Naito, N., \& Minabe, Y. (2018). Changes in maternal feelings for children with autism spectrum disorder after childbirth: The impact of knowledge about the disorder. PLoS One, 13(8), e0201862. https://doi.org/10.1371/journ al.pone.0201862

Varni, J. W., Burwinkle, T. M., Seid, M., \& Skarr, D. (2003). The PedsQL 4.0 as a pediatric population health measure: Feasibility, reliability, and validity. Ambulatory Pediatrics, 3, 329-341.

Vernhet, C., Dellapiazza, F., Blanc, N., Cousson-Gelie, F., Miot, S., Roeyers, H., \& Baghdadli, A. (2019). Coping strategies of parents of children with autism spectrum disorder: A systematic review. European Child and Adolescent Psychiatry, 28, 747-758.https:// doi.org/10.1007/s00787-018-1183-3

Wei, Y. S., Chu, H., Chen, C. H., Hsueh, Y. J., Chang, Y. S., Chang, L. I., \& Chou, K. R. (2012). Support groups for caregivers of intellectually disabled family members: Effects on physical-psychological health and social support. Journal of Clinical Nursing, 21(11-12), 1666-1677. https://doi.org/10.1111/j.1365-2702.2011. 04006.x

Publisher's Note Springer Nature remains neutral with regard to jurisdictional claims in published maps and institutional affiliations. 